\title{
Erratum to: Flourishing Across Europe: Application of a New Conceptual Framework for Defining Well-Being
}

\author{
Felicia A. Huppert • Timothy T. C. So
}

Published online: 4 April 2012

(C) Springer Science+Business Media B.V. 2012

\section{Erratum to: Soc Indic Res \\ DOI 10.1007/s11205-011-9966-7}

After the article was published online, the authors discovered that an earlier version of Table 6 had been used, which contains several typos. The authors apologise for any resulting confusion or lack of clarity. The correct version of Table 6 is presented.

The online version of the original article can be found under doi:10.1007/s11205-011-9966-7.

F. A. Huppert $(\bowtie) \cdot$ T. T. C. So

Well-Being Institute \& Department of Psychiatry, University of Cambridge,

Box 189, Addenbrooke's Hospital, Cambridge CB2 2QQ, UK

e-mail: fah2@cam.ac.uk 


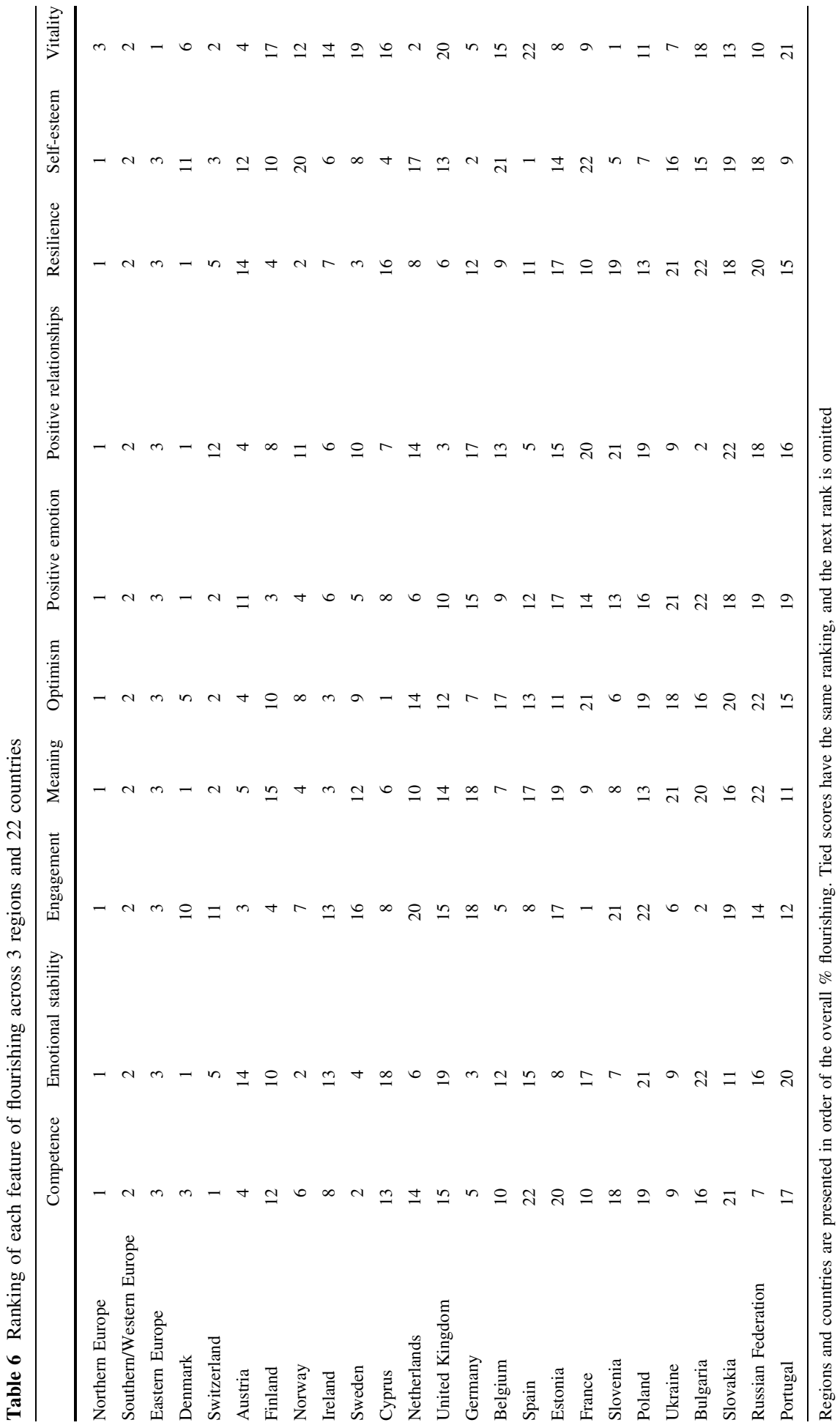

